\title{
Localized Surface Plasmon on 6H SiC with Ag Nanoparticles
}

\author{
Wei, Yi; Fadil, Ahmed; Ou, Haiyan
}

Published in:

Materials Science Forum

Link to article, DOI:

10.4028/www.scientific.net/MSF.897.634

Publication date:

2017

Document Version

Peer reviewed version

Link back to DTU Orbit

Citation (APA):

Wei, Y., Fadil, A., \& Ou, H. (2017). Localized Surface Plasmon on 6H SiC with Ag Nanoparticles. Materials Science Forum, 897, 634-637. https://doi.org/10.4028/www.scientific.net/MSF.897.634

\section{General rights}

Copyright and moral rights for the publications made accessible in the public portal are retained by the authors and/or other copyright owners and it is a condition of accessing publications that users recognise and abide by the legal requirements associated with these rights.

- Users may download and print one copy of any publication from the public portal for the purpose of private study or research.

- You may not further distribute the material or use it for any profit-making activity or commercial gain

- You may freely distribute the URL identifying the publication in the public portal

If you believe that this document breaches copyright please contact us providing details, and we will remove access to the work immediately and investigate your claim. 


\title{
Localized Surface Plasmon on SiC with Ag Nanoparticles
}

\author{
Wei, Yi; Fadil, Ahmed; Ou, Haiyan
}

Publication date:

2016

Document Version

Publisher's PDF, also known as Version of record

Link back to DTU Orbit

Citation (APA):

Wei, Y., Fadil, A., \& Ou, H. (2016). Localized Surface Plasmon on SiC with Ag Nanoparticles. Paper presented at 11 th European Conference on Silicon Carbide and Related Materials, Halkidiki, Greece.

\section{DTU Library}

\section{Technical Information Center of Denmark}

General rights

Copyright and moral rights for the publications made accessible in the public portal are retained by the authors and/or other copyright owners and it is a condition of accessing publications that users recognise and abide by the legal requirements associated with these rights.

- Users may download and print one copy of any publication from the public portal for the purpose of private study or research.

- You may not further distribute the material or use it for any profit-making activity or commercial gain

- You may freely distribute the URL identifying the publication in the public portal 


\title{
Localized Surface Plasmon on $<6 \mathrm{H}>\mathrm{SiC}$ with Ag Nanoparticles
}

\author{
Yi Wei $^{\mathrm{a}^{*}}$, Ahmed Fadil, Haiyan Ou ${ }^{\mathrm{b}^{*}}$ \\ Department of Photonics Engineering, Technical University of Denmark, DK-2800, \\ Kgs. Lyngby, Denmark



Silicon-carbide $(\mathrm{SiC})$ is a promising luminescent material since it can be applied as a substrate and wavelength conversion material for white light-emitting diode (LED) [1]. However, little work has been done on inducing localized surface plasmon (LSP) on bulk SiC surface for efficiency improvement, whereas massive accomplishments have been carried out for luminescence enhancement of quantum well based LEDs by LSP coupling [2].

In this paper, we will demonstrate our attempt on inducing LSP on N-doped $\langle 6 \mathrm{H}\rangle$ bulk SiC surface. The aim is to increase the donor-acceptor pairs (DAP) recombination rate by achieving a coupling with the LSP modes of metallic nanoparticles (NPs). DAP are expected to couple with LSP before being captured by non-radiative recombination centers [3]. The LSP-DAP coupling, which is a new path of recombination, can be very quick due to the large density of states of surface plasmon modes [4]. This way, the internal quantum efficiency (IQE) is expected to be improved.

The as-grown bulk $\langle 6 \mathrm{H}\rangle \mathrm{SiC}$ wafers (Nitrogen: $5.37 \times 10^{18}\left[\mathrm{~cm}^{-3}\right]$, Boron: $9.5 \times 10^{17}\left[\mathrm{~cm}^{-3}\right]$ ) were supplied by TanKeBlue, and 4 different thickness of Ag thin films $(5[\mathrm{~nm}] / 10[\mathrm{~nm}] / 15[\mathrm{~nm}] / 20[\mathrm{~nm}])$ were deposited on different $\mathrm{SiC}$ bare samples by e-beam evaporation. Finally, Ag NPs were selfassembled after rapid thermal annealing at $350\left[{ }^{\circ} \mathrm{C}\right]$ for $15[\mathrm{~min}]$.

The photoluminescence (PL) was excited by a diode laser with $\lambda=375[\mathrm{~nm}]$; The transmittance was measured by an integrating sphere with a white light source; For time-resolved photoluminescence (TRPL) measurement, the samples were excited by a pulsed laser source with a pulse repetition rate of $416.7[\mathrm{KHz}]$. Note that we were using front excitation and front detection (the plane with Ag NPs was considered to be front side) for both PL and TRPL measurements.

Fig. 1 shows the top-view scanning electron microscope (SEM) images of annealed Ag NPs each with different Ag thin film thickness. The calculated average diameter of Ag NPs for each deposited Ag thin films are: (a) $26.8[\mathrm{~nm}]$, (b) $74.9[\mathrm{~nm}]$, (c) $135[\mathrm{~nm}]$ and (d) $188[\mathrm{~nm}]$ respectively.

The PL spectra of the samples are shown in Fig. 2(a). All SiC samples with Ag NPs are observed to have a lower PL intensity than the as-grown SiC. Transmittance spectra of each SiC sample with $\mathrm{Ag} \mathrm{NPs}$ are shown in Fig. 2(b), where the normalization is relative to the as-grown SiC transmittance. The dips in the spectra indicated the existence of LSP resonances, and it is found that $\lambda_{\text {LSP }}$ redshifts with the size increase of Ag NPs, where $\lambda_{\text {LSP }}$ of sample "Ag_20nm" is predicted to be around infrared region. Since the $\lambda_{\text {peak }}$ in PL spectra is located closest to $\lambda_{\text {LSP }}$ of sample "Ag_10nm", it is supposed to induce more efficient LSP coupling with DAP in the substrate [4], whereas it had the lowest PL value. This is because of the non-radiative loss caused by the absorption of photons in the Ag NPs with existing LSP mode [5]. From macroscopic view, SiC samples with Ag NPs in our experiment did induce LSP, but LSP caused more absorption than scattering of energy [2]. Therefore the emission fraction [6] of SiC substrate needs to be improved further.

Fig. 2(c) shows the results of TRPL measurement and the corresponding exponential fitting curves, and Table 1 gives detailed results of exponential decay fitting with normalized amplitude , related time constant for each order and amplitude weighted photon lifetime $\left(\mathrm{t}_{\mathrm{Av}}\right)$ [7], which indicate three different recombination channels in $\mathrm{SiC}$ [8]. We find that $\tau_{3}$ has the most obvious percentage of descending as $t_{\mathrm{Av}}$ decreases, which is the minimal decay time indicating the fastest recombination channel. Meanwhile, as $\mathrm{A}_{3}$ increases with decreased $t_{\mathrm{Av}}$, it is believed that LSP has introduced more DAP into the fastest recombination channel, where $A_{3}$ has been improved from $1.76 \%$ to over $70 \%$,

\footnotetext{
* corresponding author
} 
revealing that over $65 \%$ of DAP have been switched from slow recombination channel to fast recombination channel. The improvement of the fastest recombination channel could be explained by immediate electron transfer from Ag NPs upon photoexcitation of plasmon band [9], where an injected electron will be recombined with the hole on the interface between Ag NPs and substrate, with a lifetime of less than $1[\mathrm{~ns}]$.

In conclusion, we successfully induced LSP mode on SiC substrate and found that it can switch over $65 \%$ of DAP from slow recombination channel to fast recombination channel, indicating a promising method worthy to be further investigated to improve the IQE of SiC based LEDs.

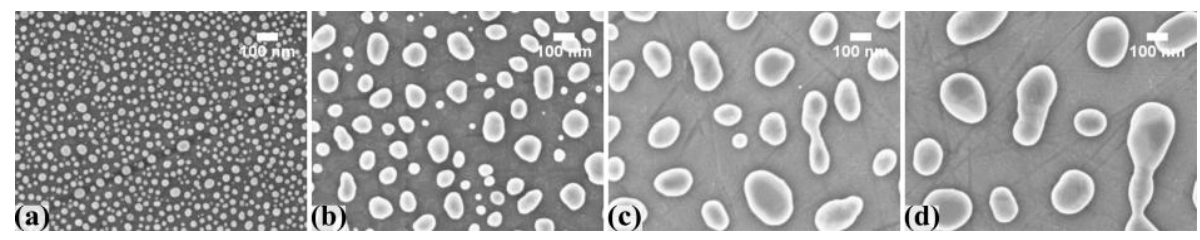

Fig. 1. The top view SEM images of annealed Ag NPs on $\langle 6 \mathrm{H}\rangle \mathrm{SiC}$ substrate with as-deposited Ag thin films of: (a) $5[\mathrm{~nm}]$; (b) $10[\mathrm{~nm}]$; (c) $15[\mathrm{~nm}]$; (d) $20[\mathrm{~nm}]$.

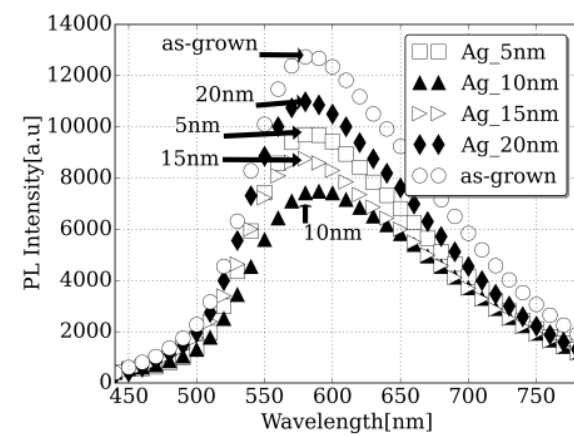

(a)

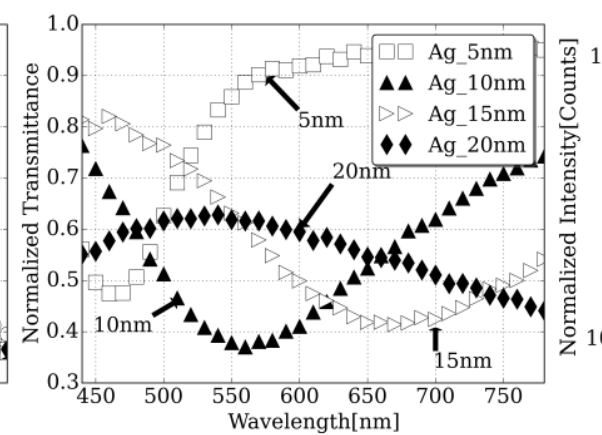

(b)



(c)

Fig. 2. Characterization of SiC samples with Ag NPs: (a) PL measurements; (b) Normalized transmittance; (c) Normalized TRPL curves and their corresponding exponential fittings.

Table 1. Exponential decay fitting results for each sample.

\begin{tabular}{cccccccc}
\hline & $\mathrm{A}_{1 \_ \text {norm[\%] }}$ & $\tau_{1}[\mathrm{~ns}]$ & $\mathrm{A}_{2 \_}$norm[\%] & $\tau_{2}[\mathrm{~ns}]$ & $\mathrm{A}_{3 \_}$norm[\%] & $\tau_{3}[\mathrm{~ns}]$ & $\mathrm{t}_{\mathrm{Av}}[\mathrm{ns}]$ \\
\hline As-grown & 93.59 & 318.4 & 4.65 & 25.31 & 1.76 & 2.387 & 82.2 \\
Ag_5nm & 10.79 & 255.3 & 17.87 & 8.33 & 71.34 & 0.465 & 29.4 \\
Ag_10nm & 16.54 & 267.5 & 21.43 & 10.3 & 62.04 & 1.221 & 47.2 \\
Ag_15nm & 4.26 & 268.1 & 9.61 & 7.12 & 86.13 & 0.3672 & 12.4 \\
Ag_20nm & 3.97 & 280.3 & 6.97 & 8.05 & 89.05 & 0.3706 & 12.0 \\
\hline
\end{tabular}

Acknowledgements. This study was supported by Innovation Fund Denmark (No. 4106-00018B).

\section{References}

[1] Ou, H., et al., (2014). European Physical Journal B, 87(3), 1-16.

[2] Fadil, A., et al., (2014). Scientific Reports, Vol. 4, 6392.

[3] Jang, L., et al., (2012). Optics Express, 20(3), 2116-2123.

[4] Okamoto, K., et al., (2005). Applied Physics Letters, 87(7), 071102.

[5] Sun G., et al., (2011). IEEE Journal on Selected Topics in Quantum Electronics, 17(1), 110118.

[6] Wang, J. Y., et al., (2007). Applied Physics Letters, 91(23), 233104.

[7] Wahl, M. (2007). Technical Note-Time-Correlated Single Photon Counting.

[8] Fan, J. Y., et al., (2011). Applied Physics Letters, 98(8), 081913.

[9] Long, R., et al., (2014). Journal of the American Chemical Society, 136(11), 4343-4354. 